\title{
Reply to comment on: Gerstein HC, Pogue J, Mann JFE et al. (2005) The relationship between dysglycaemia and cardiovascular and renal risk in diabetic and non-diabetic participants in the HOPE study: a prospective epidemiological analysis. Diabetologia 48:1749-1755
}

Received: 10 November 2005 / Accepted: 14 November 2005 / Published online: 25 January 2006

(C) Springer-Verlag 2006

To the Editor:

In his letter [1], Professor Yudkin rightly stresses that: (1) diabetes is a strong categorical risk factor for cardiovascular disease; and (2) the excess risk cannot be accounted for by classic risk factors such as dyslipidaemia and blood pressure. $\mathrm{He}$ also correctly points out that a relationship between the category of impaired glucose tolerance and cardiovascular disease has been recognised at least as far back as 1980 . However, in our original hypothesis paper in 1995 [2], we and others noted that these older data do not indicate a threshold of risk at the current impaired glucose tolerance cut-off level of $7.8 \mathrm{mmol} / \mathrm{l}$ [3]; they extend at least to 2-h glucose levels of $5.3 \mathrm{mmol} / \mathrm{l}$ [4]. Several large epidemiological studies of people without diabetes have since clearly shown that both the fasting glucose level and 2-h post-load glucose level [5] are, individually (i.e. when analysed alone as opposed to together), progressive risk factors for cardiovascular disease, with no clear evidence of a threshold. The relevance of the fasting glucose level is best highlighted in a recent systematic overview of 17 cohort studies comprising 1.2 million person-years of follow-up in 237,468 individuals with fasting glucose samples [6]. In this report, the ageadjusted risk of cardiovascular events such as stroke, ischaemic heart disease and cardiovascular death rises ap-

H. C. Gerstein $(\bowtie)$

Department of Medicine,

McMaster University and the Population Health

Research Institute,

Room 3V38, 1200 Main Street West,

Hamilton, ON L8N 3Z5, Canada

e-mail: gerstein@mcmaster.ca

Tel.: +1-905-5212100

Fax: +1-905-5214971 proximately $20 \%$ per $1 \mathrm{mmol} / \mathrm{l}$ rise in fasting glucose levels above $4.9 \mathrm{mmol} / \mathrm{l}$ in men and women; this relationship was maintained after excluding people with diabetes. A similar progressive relationship between $\mathrm{HbA}_{1} \mathrm{c}$ levels and incident cardiovascular disease has also been observed in a large population-based cohort [7], in which the significant relationship persisted after adjustment for other cardiovascular risk factors, including diabetes status.

Our epidemiological analyses of data from 2,950 Heart Outcomes Prevention Evaluation (HOPE) study participants for whom a fasting plasma glucose level was available included 1,937 subjects without diabetes [8]. It complements previous analyses of the relationship between fasting glucose and cardiovascular disease [9] by demonstrating that it is independent of several other established cardiovascular risk factors, as well as diabetes status. This independence from diabetes status implicates the degree of glucose elevation and not the presence or absence of diabetes per se as the independent risk factor, in both the current analysis and the $\mathrm{HbA}_{1} \mathrm{c}$ analysis described above [7]. Finally, the curvilinear shape of the relationship between cardiovascular risk and fasting plasma glucose (when plotted on a linear scale) is similar to (but clearly less marked than) the curvilinear relationship between nephropathy risk and fasting plasma glucose.

We completely agree that these data do not prove that the observed excess risk of cardiovascular disease is the 'consequence of dysglycaemia' and that such an inference requires evidence of reversibility in large, welldesigned clinical trials. The fact that several such large trials designed to determine whether or not glucose lowering reduces cardiovascular events are currently in progress [10] suggests that the hypothesis needs to be clearly tested and that the definitive answer remains unknown. 


\section{References}

1. Yudkin JS (2006) Comment to Gerstein HC, Pogue J, Mann JFE et al (2005) The relationship between dysglycaemia and cardiovascular and renal risk in diabetic and non-diabetic participants in the HOPE study: a prospective epidemiological analysis. Diabetologia DOI 10.1007/s00125-005-0115-1

2. Gerstein HC, Yusuf S (1996) Dysglycaemia and risk of cardiovascular disease. Lancet 347:949-950

3. Coutinho M, Gerstein HC, Wang Y, Yusuf S (1999) The relationship between glucose and incident cardiovascular events. A metaregression analysis of published data from 20 studies of 95,783 individuals followed for 12.4 years. Diabetes Care 22:233-240

4. Fuller JH, Shipley MJ, Rose G, Jarrett RJ, Keen H (1980) Coronary-heart-disease risk and impaired glucose tolerance. The Whitehall Study. Lancet 8183:1373-1376

5. DECODE Study Group, European Diabetes Epidemiology Group (2003) Is the current definition for diabetes relevant to mortality risk from all causes and cardiovascular and noncardiovascular diseases? Diabetes Care 26:688-696

6. Lawes CM, Parag V, Bennett DA et al (2004) Blood glucose and risk of cardiovascular disease in the Asia Pacific region. Diabetes Care 27:2836-2842

7. Khaw KT, Wareham N, Bingham S, Luben R, Welch A, Day N (2004) Association of hemoglobin A1c with cardiovascular disease and mortality in adults: the European prospective investigation into cancer in Norfolk. Ann Intern Med 141:413420

8. Gerstein HC, Pogue J, Mann JF et al (2005) The relationship between dysglycaemia and cardiovascular and renal risk in diabetic and non-diabetic participants in the HOPE study: a prospective epidemiological analysis. Diabetologia 48:17491755

9. Meigs JB, Nathan DM, D'Agostino RB Sr, Wilson PW (2002) Fasting and postchallenge glycemia and cardiovascular disease risk: the Framingham Offspring Study. Diabetes Care 25:18451850

10. Buse JB, Rosenstock J (2005) Prevention of cardiovascular outcomes in type 2 diabetes mellitus: trials on the horizon. Endocrinol Metab Clin North Am 34:221-235 